\title{
The influence of soil microorganisms on heavy metal content in the substrate of waste rock dumps
}

\author{
Natalia Makeeva ${ }^{1, *}$, Olga Neverova $^{2}$ \\ ${ }^{1}$ Federal Research Centre of Coal and Coal Chemistry of SB RAS, Russia \\ ${ }^{2}$ Kemerovo State University, Institute of Biology, Ecology and Natural Resources, Russia
}

\begin{abstract}
The environmental effects of mining and its impact on natural resources are of a holistic nature. One of the modern methods employed for the remediation of technogenically disturbed soils is the application of microorganisms. This paper studies the impact made by soil microorganisms on the accumulation rate of heavy metals in the substrate of waste rock dumps in the process of soil reclamation. Suspensions of soil microorganisms (microorganisms utilising mineral nitrogen forms / MUMN; microorganisms decomposing silicates / MDS; microscopic fungi / MF) were applied to the rock dump surface. Separate groups as well as their combinations were applied. The heavy metal content analysis did not indicate a significant exceedance of the maximum allowable concentration limits (MACL) in the soil of the waste rock. The only metal whose content exceeded the maximum admissible concentration limits was nickel. It has found that the application of microorganisms influences the concentration of several heavy metals due to $\mathrm{pH}$ level changes of the rock dump soil.
\end{abstract}

\section{Introduction}

The influence of mining operations on the environment and natural resources is of a multifaceted, lasting, and holistic nature. Coal-mining sites are characterised by total destruction of ecosystems and the formation of mining waste rock dumps and borrow excavations. Additionally, either soil degradation or deformation of vegetation takes place around coal-mining sites. Storing mining waste (rock dumps and spoil tips) leads to the disturbance of soil and vegetation; as a result, natural landscapes are replaced by technogenic. Such areas remain barren for a long time and are hardly suitable for active soil formation. Consequently, it is necessary to create conditions that will facilitate more productive soil self-regeneration. It is also urgent to take measures aimed at soil reclamation.

Microorganism application is a modern method for the remediation of technogenically disturbed soils. This approach became common for the reclamation of disturbed lands of various origins $[1,2]$. A growing number of microorganisms in the soil substrate is observed in as much as one year provided that microorganisms were applied, while in case

\footnotetext{
*Corresponding author: natykor@bk.ru
} 
of natural self-organised vegetation the same growth rate is achieved in only 5-8 years. Moreover, in the former case there is an advanced vegetation overgrowth of derelict lands in conjunction with improvements in agrochemical composition and plant growth processes $[3,4]$. Such positive changes result from the activity of microorganisms as they can transform low accessible forms of nutrients into more accessible to plants.

Rock dumps are not infrequently sources of pollution, the most common pollutants being heavy metals. Hence, it is also necessary to take steps to prevent their migration to the adjacent areas as well as to improve the general sanitary situation.

The aim of this research was to study the effect produced by soil microorganisms on heavy metal accumulation rate in the substrate of mining waste rock dumps.

\section{Materials and Methods}

The test sites are located on the external waste rock dump 'Southern' of the coal strip mine 'Kedrovsky' in Kemerovo Oblast. The rock dump is 25 - 30 years old. It is composed of sandstone $(60 \%)$, siltstones $(20 \%)$, argillites $(15 \%)$, loam soils and clays $(5 \%)$. The soil under study is characterised by alkaline reaction $(\mathrm{pH} 7.8)$ and a low level of labile forms of phosphorus and nitrogen. Its content of exchangeable potassium is slightly lower than normal. According to the soil texture, it is a medium-textured loam. The dominant fraction in the soil is large aggregates ( 3 to $10 \mathrm{~mm}$ and larger); they comprise $56 \%$ of the air-dry soil weight. The content of fine particles is decreased; as a result, spoil dumps exhibit low moisture holding capacity and are easily water-eroded.

A suspension of soil microorganisms (microorganisms using mineral nitrogen forms / MUMN; microorganism decomposing silicates / MDS; microscopic fungi / MF) was applied to the rock dump surface to investigate the influence of these microorganism on the properties of the rock dump soil. Separate groups as well as their combinations were applied.

Heavy metals in the rock dump soil were detected by atomic-absorption spectrophotometry in the acetylene-air flame using an AAS-30 spectrophotometer (Germany) at the accredited testing centre of the agrochemical service "Kemerovsky".

\section{Results and Discussion}

Heavy metals undergo the following transformations while penetrating into soil substrate in the process of technogenesis: oxides change to hydroxides which are then dissolved; solid soil phases adsorb cations; phosphates and their compounds with organic substances present in the soil are formed [6].

Heavy metal accretion is determined by such genetic traits as soil texture, soil organic matter content, soil cation exchange capacity, the thickness of humus horizon, and the soil $\mathrm{pH}$. It was found that cadmium, lead, zinc, copper, and nickel are significantly mobile in acidic environments. Consequently, they are leached, and their content in the surface soil horizon grows lower than the baseline concentration level. As a result, mostly lead, zinc, and copper are accrued in acidic environments, while cadmium and cobalt are accumulated in alkaline environments. Heavy soil texture, high exchange capacity, and high humus content facilitate a higher heavy metal accumulation rate [7]. Such substances as cobalt, beryllium, zinc, cadmium, tin, and lead are captured by the soil organic matter. Due to this, soils rich in humus have a higher concentration of the above-mentioned substances in comparison to nutrient-poor soils.

The evaluation of heavy metal content in the rock dump soil did not indicate a substantial exceedance of the maximum allowable concentration limits (Table 1). The only 
metal whose content exceeds the admissible limit is nickel. It is characterised by low mobility in soil and soil substrates. Nickel is mostly concentrated in the silt fraction and can form highly soluble chelate compounds with organic substances [8]. Soluble forms of nickel are actively absorbed by plant roots; nevertheless, if soil $\mathrm{pH}$ is higher than 6.7 , nickel movement to plants is hampered.

It was found that heavy metal accumulation rate in the soils of the areas adjacent to coal-mining enterprises is determined by the heavy metal concentration in the overburden rock. Therefore, it is highly probable that chemical pollution of soils increases if exploited rocks contain high concentrations of toxic elements [9]. From this perspective the overburden rocks in this rock dump presumably do not exhibit an elevated level of heavy metals which could get to the rock dump soil.

Table 1. Content of heavy metal labile fractions, $\mathrm{mg} / \mathrm{kg}$.

\begin{tabular}{|c|c|c|c|c|c|c|c|c|c|}
\hline \multirow{2}{*}{$\begin{array}{c}\text { Heavy } \\
\text { metal }\end{array}$} & \multirow{2}{*}{ MACL } & \multicolumn{9}{|c|}{ № } \\
\cline { 3 - 10 } & & 1 & 2 & 3 & 4 & 5 & 6 & 7 & 8 \\
\hline Lead & 6 & 1.61 & 1.91 & 1.63 & 2.51 & 1.98 & 1.91 & 1.72 & 1.85 \\
\hline Cadmium & - & 0.344 & 0.259 & 0.251 & 0.296 & 0.253 & 0.257 & 0.219 & 0.204 \\
\hline Copper & 3 & 1.37 & 2.06 & 1.97 & 1.55 & 1.59 & 1.49 & 1.37 & 1.46 \\
\hline Zinc & 23 & 3.24 & 2.75 & 3.03 & 2.53 & 2.85 & 2.37 & 2.27 & 2.26 \\
\hline Manganese & $140-500$ & 237.0 & 222.5 & 222.5 & 214.5 & 236.5 & 220.5 & 238.5 & 253.5 \\
\hline Nickel & 4 & 4.62 & 5.39 & 4.26 & 4.85 & 4.86 & 3.82 & 4.12 & 4.45 \\
\hline Cobalt & 5 & 3.49 & 4.34 & 3.62 & 3.88 & 3.92 & 3.10 & 3.47 & 3.89 \\
\hline Iron & - & 254 & 255.5 & 235.5 & 266 & 262 & 237 & 264.5 & 274.5 \\
\hline Chromium & 6 & 6.89 & 4.63 & 2.82 & 3.87 & 3.18 & 4.23 & 4.43 & 3.98 \\
\hline
\end{tabular}

Note. 1 - Control; $2-M F ; 3-M D S ; 4-M U M N ; 5-M F+M D S ; 6-M F+M U M N ; 7-$ $M D S+M U M N ; 8-M D S+M F+M U M N$.

It is interesting to note that the content of copper and lead during the application of soil microorganisms exceeded the control values. In addition, there was more lead when microorganisms utilising mineral nitrogen were applied (control values were exceeded by $56 \%$ ). In the tests with microscopic fungi (MF, MF + MDS, MF + MUMN, MDS + MF + MUMN) the control values were exceeded by $7-23 \%$. The maximum copper content was registered when microscopic fungi and microorganism decomposing silicates were applied. In this case the control values were exceeded by $50 \%$ and $44 \%$ respectively, which is probably caused by the change of the rock dump $\mathrm{pH}$ level triggered by the application of microorganism suspensions. What is more, relevant research shows that there is an increase in heavy metals in the rhizosphere of agricultural plants as the products of microorganism vital activity are bound. Thus, heavy metal absorption by plant roots is prevented $[10,11]$.

\section{Conclusion}

In summary, the performed research indicated that the content of most heavy metals in the waste rocks of the Kedrovsky coal strip mine is within normal limits. The elevated level of nickel at the test site necessitates monitoring in order to control the nickel content in the rock substrates.

The paper was prepared according to state task № 0286-2021-0010 "The development of a scientific basis for assessing the condition and the recovery of floristic diversity in situ and ex situ in the areas with high degradation of ecosystems due to anthropogenic and technogenic impact".

\section{References}


1. A. Borem, F.R. Santos, D.E. Bowen, Understanding Biotechnology (Prentice Hall PTR, 2003)

2. G.M. Evans, J.C. Furlong, Environmental biotechnology: theory and application (University of Durham, UK and Taeus Biotech Ltd., 2003)

3. N.A. Makeeva, O.A. Neverova, Modern problems of science and education 6, 601 (2015)

4. N.A. Makeeva, O.A. Neverova, Advances of modern science 7, 76-80 (2016)

5. Methodological guidelines for detecting heavy metals in agricultural field soils and plant produce 65 (CIAS, Moscow, 1992)

6. M.A. Yakovchenko, O.B. Konstantinova, A.A. Kosolapova, L.V. Rogova, D.N. Alankina, Bulletin of KuzSTU 3, 116-119 (2014)

7. A.S. Voronkova, Mining information-analytical bulletin 1 (2006)

8. S.V. Lukin Achievements of science and technology AIC 3, 14-15 (2011)

9. A.P. Krasavin, I.V. Katayeva, A.V. Ostanin, V.A. Yekaterininsky, Plants and industrial environment 128-135 (1992)

10. M.S. Panin, Ye.N. Biryukova, G.V. Motuzova, Modern problems of soil pollution 72 75 (Moscow, 2004)

11. A.I. Puzakova, I.S. Konyaev, I.V. Prokopenko, A.Ye. Tigunov, Samara Bend: regional and global environmental problems 21, 148-151 (2012) 